\title{
Anthocyanins inhibit high glucose-induced renal tubular cell apoptosis caused by oxidative stress in $\mathrm{db} / \mathrm{db}$ mice
}

\author{
JINYING WEI ${ }^{1,2^{*}}$, HAIJIANG WU ${ }^{1,2^{*}}$, HAIQIANG ZHANG ${ }^{3}$, FANG LI $^{1,2}$, SHURUI CHEN $^{1,2}$, \\ BAOHUA HOU ${ }^{1,2}$, YONGHONG SHI ${ }^{1,2^{*}}$, LIJUAN ZHAO ${ }^{4}$ and HUIJUN DUAN ${ }^{1,2}$ \\ ${ }^{1}$ Department of Pathology, Hebei Medical University; ${ }^{2}$ Key Laboratory of Kidney Diseases of Hebei Province, \\ Shijiazhuang, Hebei 050017; ${ }^{3}$ Department of Gastrointestinal Surgery Hernia and Abdominal Wall Surgery, \\ The Second Hospital of Hebei Medical University, Shijiazhuang, Hebei 050000; \\ ${ }^{4}$ School of Public Health, Hebei Medical University, Shijiazhuang, Hebei 050017, P.R. China
}

Received June 12, 2017; Accepted January 4, 2018

DOI: $10.3892 / \mathrm{ijmm} .2018 .3378$

\begin{abstract}
Oxidative stress is an important contributory factor resulting the development of kidney injury in patients with diabetes. Numerous in vitro and in vivo studies have suggested that anthocyanins, natural phenols commonly existing in numerous fruits and vegetables, exhibit important antioxidative, anti-inflammatory and antihyperlipidemic effects; however, their effects and underlying mechanisms on diabetic nephropathy (DN) have not yet been fully determined. In the present study, the regulation of apoptosis metabolism and antioxidative effects exhibited by anthocyanins [grape seed procyanidin (GSPE) and cyanidin-3-O- $\beta$-glucoside chloride $(\mathrm{C} 3 \mathrm{G})]$ were investigated, and the molecular mechanism underlying this process was investigated in vivo and in vitro. GSPE administration was revealed to suppress renal cell apoptosis, as well as suppress the expression of Bcl-2 in diabetic mouse kidneys. Furthermore, GSPE administration was demonstrated to suppress the expression of thioredoxin interacting protein (TXNIP), in addition to enhancing p38 mitogen-activation protein kinase (MAPK) and extracellular signal-regulated kinase 1/2 (ERK1/2) oxidase activity in diabetic mouse kidneys. In vitro experiments using HK-2 cells revealed that C3G suppressed the generation of HG-mediated reactive oxygen species, cellular apoptosis, the expression of cleaved caspase- 3 and the $\mathrm{Bax} / \mathrm{Bcl}-2$ ratio; and enhanced the expression of cytochrome $c$ released from mitochondria. Furthermore, treatment with $\mathrm{C} 3 \mathrm{G}$ was revealed to suppress the expression of TXNIP, in addition to the phosphorylation of
\end{abstract}

Correspondence to: Professor Yonghong Shi, Department of Pathology, Hebei Medical University, 361 East Zhongshan Road, Shijiazhuang, Hebei 050017, P.R. China

E-mail: yonghongshi@163.com

*Contributed equally

Key words: diabetic nephropathy, apoptosis, reactive oxygen species, thioredoxin interaction protein, anthocyanins p38 MAPK and ERK1/2 oxidase activity in HK-2 cells under HG conditions. In addition, treatment with $\mathrm{C} 3 \mathrm{G}$ was revealed to attenuate the HG-induced suppression of the biological activity of thioredoxin, and to enhance the expression of thioredoxin 2 in HK-2 cells under HG conditions. In conclusion, the present study demonstrated that anthocyanins may exhibit protective effects against HG-induced renal injury in DN via antioxidant activity.

\section{Introduction}

Diabetic nephropathy (DN) is a primary complication of diabetes mellitus. Oxidative stress has been suggested to have an important role in DN (1). The loss of resident renal tubular epithelial cells via apoptosis has been demonstrated in experimental DN, and renal tubular epithelial cell apoptosis has been demonstrated to be associated with the progression of albuminuria (2). Normal cellular metabolism may produce reactive oxygen species (ROS), and it has previously been revealed that a number of environmental factors, including exposure to chemical agents, may induce oxidative stress (3). The physiological levels of ROS have important roles in intracellular signal transduction, follicle development, ovulation and gene expression $(4,5)$. Furthermore, excessive ROS production may result in oxidative stress. According to previous studies, it has been suggested that the suppression of high glucose (HG)-induced apoptosis in tubular cells is a predominant cause of renal injury in patients with diabetes $(6,7)$. The hyperglycemia-induced production of ROS has an important role in the progression of DN (8). It has been revealed that HG-induced renal tubular epithelial cellular apoptosis is significantly decreased following the administration of $\mathrm{N}$-acetylcysteine and ascorbic acid antioxidants $(9,10)$. Numerous studies have demonstrated that HG induces the apoptosis of renal tubular epithelial cells via an oxidant-dependent mechanism. Therefore, the inhibition of oxidative stress may serve as a potential therapeutic target for the treatment of DN.

A previous study demonstrated that the intake of naturally grown fresh vegetables and fruits attenuates the progression of diabetes and associated complications (11). For example, anthocyanins, the largest group of water-soluble pigments, belong 
to a family of phenolic flavonoid compounds that affect the pigment of numerous plants. Anthocyanins have been demonstrated to exhibit marked antioxidative properties in animal models of diabetes mellitus and to exhibit protective effects against hyperglycemia-induced kidney injury $(12,13)$. In the present study, in vivo and in vitro experiments were performed to investigate the regulation of apoptosis metabolism and the antioxidative effects exhibited by anthocyanins [grape seed procyanidin (GSPE) and cyanidin cyanidin-3-O- $\beta$-glucoside chloride $(\mathrm{C} 3 \mathrm{G})]$ in $\mathrm{db} / \mathrm{db}$ mice. Furthermore, the present study aimed to investigate the molecular mechanism underlying this process using HG-stimulated HK-2 cells.

\section{Materials and methods}

Animals and treatment. Non-diabetic littermate, 6-8 weeks of age, control male $\mathrm{db} / \mathrm{m}$ mice and male BKS db/db C57BL6 mice (body weight 40 $2.5 \mathrm{~g}$; total no. of mice, 40) were purchased from the Model Animal Research Center of Nanjing University (Nanjing, China). According to the guidelines of the National Institutes of Health (Bethesda, MD, USA), all experimental animals were housed in pathogen-free conditions with clean sawdust bedding. All mice were acclimated for 1 week prior to use and housed in polypropylene cages $(30 \times 21 \times 10 \mathrm{~cm})$, with free access to food and water, a $12 \mathrm{~h}$ light-dark cycle and a constant temperature of $23 \pm 2{ }^{\circ} \mathrm{C}$ and a humidity of $50-60 \%$. All procedures and experiments involving mice were reviewed and approved by the Ethics Committee of Hebei Medical University (Shijiazhuang, China). At the age of 8 weeks, the mice were divided randomly into 4 groups: Control group $(\mathrm{db} / \mathrm{m}$ mice; $\mathrm{n}=10), \mathrm{db} / \mathrm{m}+\mathrm{GSPE}$ group $(\mathrm{db} / \mathrm{m}$ mice treated with GSPE; $n=10)$, diabetes group (db/db mice; $n=10)$ and $\mathrm{db} / \mathrm{db}+$ GSPE group (db/db mice treated with GSPE; $\mathrm{n}=10$ ). GSPE was dissolved in normal saline and administered to mice (once per day) intraperitoneally. GSPE (30 mg/kg body weight/day; Beijing Solarbio Science and Technology Co., Ltd., Beijing, China; purity $\geq 95 \%$ ) was dissolved in normal saline and administered to mice intragastrically for 12 weeks (once per day). The mice in the control group and the diabetes groups were administered the same quantity of normal saline (once per day). At the age of 20 weeks, the mice were placed in individual metabolic cages in order to collect urine samples over a 24-h time period. Prior to blood sample collection, mice fasted for $6 \mathrm{~h}$ following the termination of experiments. Plasma and urinary supernatants were frozen and then stored at $-80^{\circ} \mathrm{C}$ for further analysis. Following this, animals were sacrificed and kidneys were subsequently stored for further analysis.

Cell isolation, culture and treatment. HK-2 cells were purchased from the American Type Culture Collection (Manassas, VA, USA), and cultured in Dulbecco's modified Eagle's medium (DMEM)-F12 medium (3:1) supplemented with 5\% fetal bovine serum (both Beijing Solarbio Science and Technology Co., Ltd.) 2 mM l-glutamine, $100 \mathrm{U} / \mathrm{ml}$ penicillin and $100 \mu \mathrm{g} / \mathrm{ml}$ streptomycin at $37^{\circ} \mathrm{C}$ in a $95 \%$ air-5\% $\mathrm{CO}_{2}$ atmosphere. HK-2 cells were grown to $75-85 \%$ confluence, washed once with serum-free DMEM-F12, and growth-arrested in serum-free DMEM-F12 at $37^{\circ} \mathrm{C}$ for $24 \mathrm{~h}$ in order to synchronize cell growth. Following this, cells were treated with normal glucose (NG; $5.6 \mathrm{mM}), \mathrm{HG}(30 \mathrm{mM})$,
NG plus mannitol (24.4 mM) as an osmotic control, HG plus C3G [50 $\mu \mathrm{M}(14)]$, HG plus SB203580 $(10 \mu \mathrm{M})$, or HG plus PD98059 $(50 \mu \mathrm{M})$ for $48 \mathrm{~h}$.

Immunohistochemistry analysis. All samples were incubated with $4 \%$ paraformaldehyde at room temperature for $12 \mathrm{~h}$ and then embedded in paraffin for immunohistochemical analysis used light microscope (magnification, x400). Paraffin sections were cut into 4-mm sections, deparaffinized using xylene, and rehydrated using gradient alcohol. Internal peroxidase was inactivated using $3 \%$ hydrogen peroxide in $100 \%$ methanol at room temperature for $30 \mathrm{~min}$. Antigen retrieval was performed via incubation with $10 \mathrm{mM}$ citrate buffer at room temperature for $15 \mathrm{~min}$. To block nonspecific antibody binding, sections were incubated with $10 \%$ normal goat serum (Beijing Solarbio Science and Technology Co., Ltd.) in PBS for $30 \mathrm{~min}$ at room temperature. The sections were then incubated overnight at $4^{\circ} \mathrm{C}$ with primary antibodies for thioredoxin interacting protein (TXNIP; 1:300; cat. no. ab86983), B-cell lymphoma-2 (Bcl-2; 1:350; cat. no. ab7973) and Bcl-2-associated X protein (Bax; 1:300; cat. no. ab7977) (all from Abcam, Cambridge, UK). Following washing with PBS, sections were incubated with biotinylated secondary antibodies (SP-9000; 1:4,000; cat. no. 004-2013; ZSGB-BIO; OriGene Technologies, Inc., Beijing, China) and horseradish peroxidase-conjugated streptavidin at $37^{\circ} \mathrm{C}$ for $2 \mathrm{~h}$. Chromogen detection was performed using $3,3^{\prime}$-diaminobenzidine at room temperature for $2-3 \mathrm{~min}$ to produce a brown color, and sections were then counterstained using hematoxylin at room temperature for 1-2 min. Negative controls were not incubated with primary antibodies.

Determination of intracellular and urinary ROS. The intracellular formation of ROS was determined using the fluorescence probe 5-(and 6) chloromethyl-2',7'-dichlorodihydrofluorescein diacetate (Invitrogen; Thermo Fisher Scientific, Inc., Waltham, MA, USA). Following incubation in 6-well plates under the different experimental conditions at room temperature for $48 \mathrm{~h}$, the cells were washed, trypsinized, suspended in PBS, loaded with $10 \mu \mathrm{M}$ dichloro-dihydro-fluorescein diacetate, and incubated at $37^{\circ} \mathrm{C}$ for $30 \mathrm{~min}$. ROS levels were determined using a flow cytometer (BD Biosciences, Franklin Lakes, NJ, USA). To remove particulates, urine samples were centrifuged at $600 \mathrm{x} \mathrm{g}$ for $10 \mathrm{~min}$. The supernatants were removed, and 8-hydroxy-2-deoxyguanosine levels were determined using a competitive in vitro ELISA kit (cat. no. YH8802; Nanjing Jiancheng Bioengineering Institute, Nanjing, China), in accordance with the manufacturer's protocol.

Analysis of mitochondrial membrane potential (MMP). MMP was investigated using JC-1 (Shanghai Genmed Pharmaceutical Technology, Co., Ltd., Shanghai, China) staining. Cells were seeded in $60 \mathrm{~mm}$ culture dishes $\left(2.5 \times 10^{5}\right.$ cells/well $)$ and incubated with $5 \mathrm{mM}$ JC-1 dye (Shanghai Genmed Pharmaceutical Technology, Co., Ltd.) at $37^{\circ} \mathrm{C}$ for $15 \mathrm{~min}$. Cells were washed three times with PBS and immediately analyzed using a confocal microscope (magnification, x400; DM4000B; Leica Microsystems GmbH, Wetzlar, Germany). The MMP loss was quantified via the shift of JC-1 emission from red $(\sim 590 \mathrm{~nm})$ to green $(\sim 525 \mathrm{~nm})$. Red emission 
revealed membrane potential-dependent JC-1 aggregates in the mitochondria. Green fluorescence revealed the monomeric form of JC-1 entering the cytoplasm following mitochondrial membrane depolarization. This assay functions on the basis of an electrochemical proton gradient at the mitochondrial inner membrane (15).

Thioredoxin (TRX) activity analysis. TRX activity was determined using the insulin disulfide reduction assay, as previously described (16). Following incubation of the cells in 6-well plates under the different experimental conditions for $48 \mathrm{~h}$, total cellular protein was extracted using a lysis buffer (cat. no. P0013G; Nanjing Jiancheng Bioengineering Institute). A total of $40 \mu 1$ reaction mixture [200 $\mu$ l HEPES buffer (1 M, pH 7.6), $40 \mu 1$ EDTA (0.2 M), $40 \mu 1 \mathrm{NADPH}$ $(40 \mathrm{mg} / \mathrm{ml})$ and $500 \mu \mathrm{l}$ insulin $(10 \mathrm{mg} / \mathrm{ml})]$ was incubated with cellular protein extracts at $37^{\circ} \mathrm{C}$ for $15 \mathrm{~min}$ following the administration of $10 \mu 1$ bovine TRX reductase (Sekisui Diagnostics, LLC, Lexington, MA, USA). The reaction was terminated by the administration of $500 \mu 1$ stop mix (6 M guanidine $\mathrm{HCl}, 1 \mathrm{mM}$ DTNB in $0.2 \mathrm{M}$ Tris $\mathrm{HCl} \mathrm{pH} 8.0$ ), and then the absorption at a wavelength of $412 \mathrm{~nm}$ was determined by Rayto RT-9600 semi-automatic biochemical analyzer (Rayto Life and Analytical Sciences Co., Ltd., Shenzhen, China).

Apoptosis analysis. The apoptosis of proximal tubular epithelial cells was investigated using a terminal deoxynucleotidyl transferase-mediated dUTP nick end labeling (TUNEL) assay kit (Promega Corp., Madison, WI, USA). The TUNEL assay was performed in accordance with the manufacturer's instructions. Fluorescence images were obtained using a laser-scanning confocal microscope (magnification, x400; Leica Microsystems $\mathrm{GmbH}$ ). A total of 6 fields of each coverslip were randomly selected for counting, and 100 cells were randomly counted from each field of vision. The numbers of apoptotic cells and the total number of cells were counted for all 6 fields of vision. The apoptosis rate was subsequently determined.

Following this, slides were immersed in $4 \%$ formaldehyde in PBS at $4^{\circ} \mathrm{C}$ for $10 \mathrm{~min}$ and then incubated in $0.2 \%$ Triton $\mathrm{X}-100$ in PBS for $10 \mathrm{~min}$ at room temperature. Equilibration Buffer (100 $\mu \mathrm{l}$; Promega Corp.) was added to the cells at room temperature for $10 \mathrm{~min}$, followed by $50 \mu 1$ terminal deoxynucleotidyl transferase reaction mix for $60 \mathrm{~min}$ at $37^{\circ} \mathrm{C}$. Subsequently, slides were immersed in 2X saline-sodium citrate and propidium iodide (PI; 1:10,000), at room temperature for $15 \mathrm{~min}$, was used to stain all cells. Green fluorescence of apoptotic cells on a red background was imaged using fluorescence microscopy. In order to quantify the number of TUNEL-positive (apoptotic) cells, $\geq 200$ cells were counted per group and the percentage of positively-labeled cells was determined.

The number of apoptotic cells in different groups was determined using an Annexin V/PI apoptosis detection kit according to the manufacturer's protocol (MultiSciences Biotech, Co., Ltd., Hangzhou, China). Briefly, the cell pellet was resuspended in $1 \mathrm{X}$ binding buffer and incubated with $5 \mathrm{ml}$ Annexin V (conjugated with fluorescein isothiocyanate) and $10 \mathrm{ml}$ PI in the dark at room temperature for $5 \mathrm{~min}$. Cell fluorescence was analyzed using a flow cytometer (BD Biosciences). This assay was used to discriminate between intact cells (Annexin $\mathrm{V}^{-} / \mathrm{PI}^{-}$), early apoptotic cells (Annexin $\mathrm{V}^{+} / \mathrm{PI}^{-}$) and late apoptotic cells (Annexin $\mathrm{V}^{+} / \mathrm{PI}^{+}$).

Western blot analysis. All cells were isolated via scraping in lysis buffer (cat. no. P0013G; Nanjing Jiancheng Bioengineering Institute). The protein concentration was determined using Coomassie Protein assay reagent (Sigma-Aldrich; Merck KGaA, Darmstadt, Germany). A total of $40 \mu \mathrm{g}$ proteins was loaded in each lane, separated by electrophoresis on a $30 \%$ gel, and transferred to polyvinylidene fluoride membranes. Membranes were blocked with $5 \%$ dry milk at $37^{\circ} \mathrm{C}$ for $2 \mathrm{~h}$ and incubated overnight at $4^{\circ} \mathrm{C}$ with primary antibodies. Following washing, the membranes, at room temperature for $45 \mathrm{~min}$, were incubated with goat anti-rabbit or mouse immunoglobulin G horseradish peroxidase conjugate (1:5,000; cat. nos. SA00001-2 and SA00001-1; ProteinTech Group, Inc., Chicago, IL, USA). In order to perform western blotting analysis, membranes were hybridized with the following primary antibodies: Rabbit Bax (1:1,000; cat. no. ab7977), Bcl-2 (1:1,000; cat. no. ab7973), TXNIP (1:1,000; cat. no. ab86983) (all from Abcam), cleaved caspase-3 (Asp175; 1:1,000; cat. no. 9661; Cell Signaling Technology, Inc., Danvers, MA, USA), caspase-3 (1:1,000; cat. no. 19677-1-AP), thioredoxin 2 (TRX2; 1:1,000; cat. no. 13089-1-AP) (both from ProteinTech Group, Inc.), p-p38 MAPK (Thr180/Tyr182; 1:1,000; cat. no. 4092; Cell Signaling Technology, Inc.), p-ERK1/2 (Thr202/Tyr204; 1:1,000; cat. no. 1150), p38 MAPK (1:1,000; cat. no. 9212), ERK1/2 (1:1,000; cat. no. 1240) (all from Cell Signaling Technology, Inc.), and mouse antibody cytochrome $c$ (cyt $c$; 1:2,000; cat. no. sc-514435; Santa Cruz Biotechnology, Inc., Dallas, TX, USA). Subsequently, the membranes were incubated with goat anti-rabbit or mouse IgG horseradish peroxidase conjugate, and scanned using the Odyssey Fc System (LI-COR Biosciences, Lincoln, NE, USA). The density of the bands was quantified using LabWorks 4.5 software (UVP, LLC, Phoenix, AZ, USA). Protein expression was quantified via comparison with the internal control, $\beta$-actin (1:2,000; cat. no. 60008-1-Lg; ProteinTech Group, Inc.).

Reverse transcription-quantitative polymerase chain reaction (RT-qPCR) analysis. Total RNA was isolated from granulosa cells using TRIzol reagent (Invitrogen; Thermo Fisher Scientific, Inc.), according to the manufacturer's protocol. The first complementary DNA strand was synthesized using PrimeScript RT Master Mix (Takara Biotechnology Co., Ltd., Dalian, China). The primers used for amplification were as follows: Bax sense, 5'-GCTTGCTTCAGGGTTTCATCCA-3' and antisense, 5'-TGTCCACGGCGGCAATCATC-3'; Bcl-2 sense, 5'-GGCGGAGAACAGGGTACGATAAC-3' and antisense, 5'-CGGGATGCGGCTGGATGGGG-3'; TXNIP sense, 5'-CCGTTAGGATCCTGGCTTGC-3' and antisense, 5'-GGCGCCTTGTACTCATATTTGTTTC-3'; 18s rRNA sense, 5'-ACACGGACAGGATTGACAGA-3' and antisense, 5'-GGACATCTAAGGGCATCACAG-3'. The 18s rRNA was used for normalization. RT-qPCR was performed in a 96-well optical reaction plate using SYBR Premix Ex TaqII (Takara Biotechnology Co., Ltd.). The PCR amplification began with a 5 -min denaturation at $95^{\circ} \mathrm{C}$, followed by 40 cycles of 
denaturation at $95^{\circ} \mathrm{C}$ for $45 \mathrm{sec}$, annealing at $55^{\circ} \mathrm{C}$ for $45 \mathrm{sec}$, and extension at $72^{\circ} \mathrm{C}$ for $60 \mathrm{sec}$. The final extension was set for $10 \mathrm{~min}$ at $72^{\circ} \mathrm{C}$. PCR experiments were performed on an Agilent Mx3000P qPCR System (Agilent Technologies, Inc., Santa Clara, CA, USA). Relative expression levels were determined using the $2^{-\Delta \Delta \mathrm{Cq}}$ method (17).

Statistical analysis. All data presented in bar graphs are expressed as mean \pm standard deviation. Experiments were performed in triplicate, and data were analyzed using SPSS 15.0 for Windows (SPSS, Inc., Chicago, IL, USA). One-way analysis of variance was followed by Dunnett's test for multiple comparisons. $\mathrm{P}<0.05$ was considered to indicate a statistically significant difference.

\section{Results}

Treatment with GSPE reduces the body weight and the fasting blood glucose (FBG), blood urea nitrogen, serum creatinine, triglyceride, ROS and urine albumin excretion (UAE) levels in $d b / d b$ mice. In order to investigate the role of GSPE in the progression of $\mathrm{DN}$ in $\mathrm{db} / \mathrm{db}$ mice, 8 -week-old $\mathrm{db} / \mathrm{db}$ mice were intragastrically administered $30 \mathrm{mg} / \mathrm{kg}$ GSPE (dissolved in water) every second day for 12 weeks. Total body weight and the FBG level of mice at the termination of the experiments were determined, and the results are presented in Fig. 1. The body weight and FBG levels were significantly enhanced in the $\mathrm{db} / \mathrm{db}$ group compared with the $\mathrm{db} / \mathrm{m}$ group. Treatment of $\mathrm{db} / \mathrm{db}$ mice with GSPE suppressed the increase in body weight. However, treatment with GSPE significantly increased the body weight of the $\mathrm{db} / \mathrm{db}+$ GSPE group compared with the $\mathrm{db} / \mathrm{db}$ group. All db/db mice exhibited markedly increased blood glucose levels compared with $\mathrm{db} / \mathrm{m}$ mice. Furthermore, $\mathrm{db} / \mathrm{db}$ mice treated with GSPE demonstrated significantly decreased blood glucose levels compared with non-treated $\mathrm{db} / \mathrm{db}$ mice following 12 weeks of treatment. In addition, the exhibited levels of blood urea nitrogen, serum creatinine, were significantly enhanced in the $\mathrm{db} / \mathrm{db}$ group compared with the $\mathrm{db} / \mathrm{m}$ group, however, this was significantly attenuated following treatment with GSPE (Table I). These results suggested that GSPE administration significantly stabilized metabolic parameters and preserved the renal function of $\mathrm{db} / \mathrm{db}$ mice. Furthermore, the levels of ROS [8-Oxo-2'-deoxyguanosine (8-OHdG)] were significantly elevated in the $\mathrm{db} / \mathrm{db}$ group compared with the control group (Table I). However, this effect was attenuated via GSPE administration in the $\mathrm{db} / \mathrm{db}+$ GSPE group. There were no significant differences regarding the biochemical and physical characteristics between the control group and control + GSPE group.

Treatment with GSPE suppresses the apoptosis of renal tubular cells in $\mathrm{db} / \mathrm{db}$ mice. The level of apoptosis of renal tubular cells was determined using the TUNEL assay. The $\mathrm{db} / \mathrm{db}$ group exhibited enhanced levels of renal tubular cell apoptosis compared with the control group (Fig. 2). This effect was significantly attenuated following treatment with GSPE in the $\mathrm{db} / \mathrm{db}+\mathrm{GSPE}$ group (Fig. 2).

Expression of apoptosis-associated proteins in the kidneys of $\mathrm{db} / \mathrm{db}$ mice is suppressed following treatment with GSPE. To
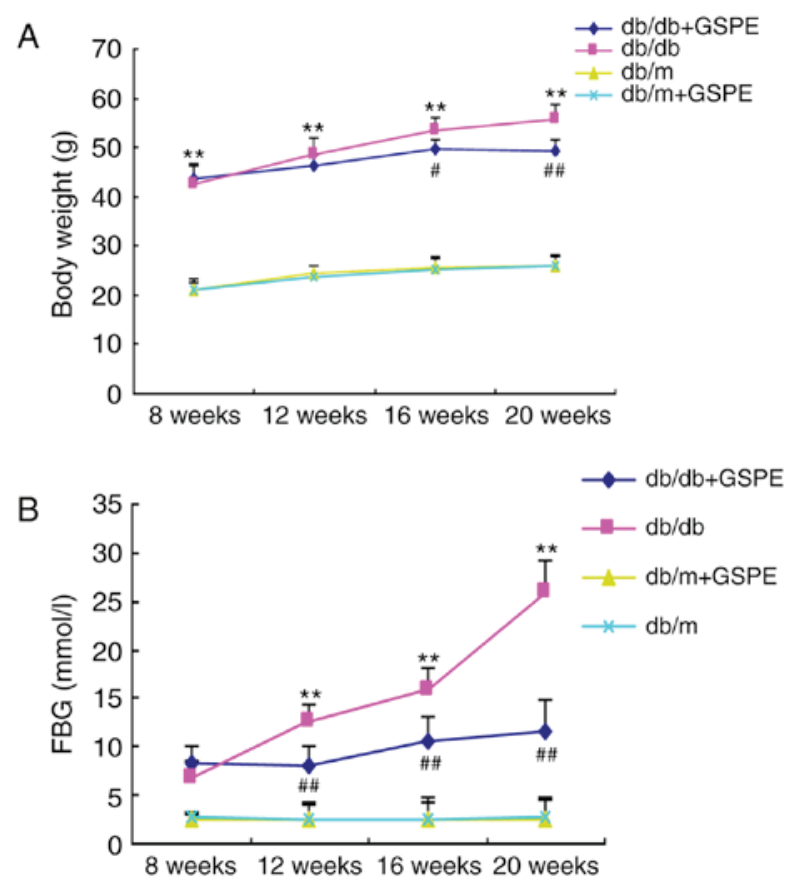

Figure 1. Treatment with GSPE suppresses (A) body weight and (B) FBG excretion in diabetic mice. All values are expressed as the mean \pm standard deviation. ${ }^{* *} \mathrm{P}<0.01$ vs. $\mathrm{db} / \mathrm{m}$ group; ${ }^{\#} \mathrm{P}<0.05$ and ${ }^{\# \#} \mathrm{P}<0.01$ vs. $\mathrm{db} / \mathrm{db}$ group. FBG, fasting blood glucose; GSPE, grape seed procyanidin.

further investigate the renal protective effects of GSPE administration in $\mathrm{db} / \mathrm{db}$ mice, apoptosis-associated protein expression levels were determined via western blotting. As demonstrated in Fig. 3A and B, the Bax/Bcl-2 ratio was suppressed and cleaved caspase- 3 was markedly increased in $\mathrm{db} / \mathrm{db}$ mice compared with $\mathrm{db} / \mathrm{m}$ mice. As revealed in Fig. $3 \mathrm{C}$ and $\mathrm{D}$, the expression level of TXNIP was markedly enhanced in $\mathrm{db} / \mathrm{db}$ mice, and treatment with GSPE markedly suppressed TXNIP expression in $\mathrm{db} / \mathrm{db}$ mice. This suggests that there is enhanced intrinsic apoptosis in the kidneys of $\mathrm{db} / \mathrm{db}$ mice compared with $\mathrm{db} / \mathrm{m}$ mice; however, treatment with GSPE significantly attenuated these effects.

GSPE inhibits the phosphorylation of ERK1/2, p38 MAPK in $\mathrm{db} / \mathrm{db}$ mice kidneys. The level of cyt $c$, in addition to the p-ERK1/2/ERK1/2 and p-p38/p38 ratios, was investigated in the kidneys of $\mathrm{db} / \mathrm{db}$ mice via western blotting. The results revealed that the level of cyt $c$ (Fig. $3 \mathrm{E}$ and $\mathrm{F}$ ), in addition to the p-ERK1/2/ERK1/2 and p-p38/p38 ratios (Fig. 4), were significantly enhanced in $\mathrm{db} / \mathrm{db}$ mice compared with $\mathrm{db} / \mathrm{m}$ mice. Furthermore, treatment with GSPE in $\mathrm{db} / \mathrm{db}$ mice was demonstrated to significantly attenuate these effects.

$C 3 G$ protects $H K-2$ cells from $H G$-induced apoptosis. To investigate whether treatment with $\mathrm{C} 3 \mathrm{G}$ protects $\mathrm{HK}-2$ cells from oxidative stress, primary cultured cells were exposed to HG conditions. Annexin V/PI staining of HK-2 cells isolated from $\mathrm{C} 3 \mathrm{G}$-pretreated groups was significantly reduced compared with the HG-treated group (Fig. 5A). In addition, RT-qPCR analysis was performed in order to determine the mRNA expression levels of caspase-3, Bax and Bcl-2 (Fig. 5B). The results suggested that the $\mathrm{Bcl}-2 / \mathrm{Bax}$ and cleaved caspase-3/caspase-3 ratios were significantly suppressed in 
Table I. Physical and metabolic parameters among different groups.

\begin{tabular}{|c|c|c|c|c|}
\hline Parameters & $\mathrm{db} / \mathrm{m}$ & $\mathrm{db} / \mathrm{m}+\mathrm{GSPE}$ & $\mathrm{db} / \mathrm{db}$ & $\mathrm{db} / \mathrm{db}+\mathrm{GSPE}$ \\
\hline $\operatorname{Scr}(\mu \mathrm{mol} / \mathrm{l})$ & $6.92 \pm 2.76$ & $6.67 \pm 3.38$ & $11.48 \pm 2.06^{\mathrm{a}}$ & $8.52 \pm 5.81^{\mathrm{c}}$ \\
\hline Upro (mg/24 h) & $7.16 \pm 2.32$ & $6.07 \pm 1.92$ & $29.91 \pm 10.01^{\mathrm{b}}$ & $19.96 \pm 6.13^{c}$ \\
\hline BUN (mmol/l) & $4.08 \pm 1.31$ & $5.91 \pm 2.28$ & $20.43 \pm 10.41^{\mathrm{b}}$ & $11.82 \pm 2.19^{c}$ \\
\hline 8-OHdG (ng/ml) & $27.01 \pm 1.67$ & $26.08 \pm 2.19$ & $60.04 \pm 3.04^{\mathrm{b}}$ & $31.23 \pm 2.28^{\mathrm{d}}$ \\
\hline
\end{tabular}

Treatment with GSPE suppresses Upro, Scr, BUN and urinary 8-OHdG excretions in diabetic mice. All values are expressed as the mean \pm standard deviation. ${ }^{\mathrm{a}} \mathrm{P}<0.05 \mathrm{vs}$. db/m group; ${ }^{\mathrm{b}} \mathrm{P}<0.01 \mathrm{vs}$. db/m group; ${ }^{\mathrm{C}} \mathrm{P}<0.05 \mathrm{vs}$. $\mathrm{db} / \mathrm{db}$ group; ${ }^{\mathrm{d}} \mathrm{P}<0.01 \mathrm{vs}$. db/db group. $8-\mathrm{OHdG}, \mathrm{Urea}$ 8-hydroxydeoxyguanosine; upro, urine protein; BUN, blood urea nitrogen; Scr, blood creatinine; GSPE, grape seed procyanidin.
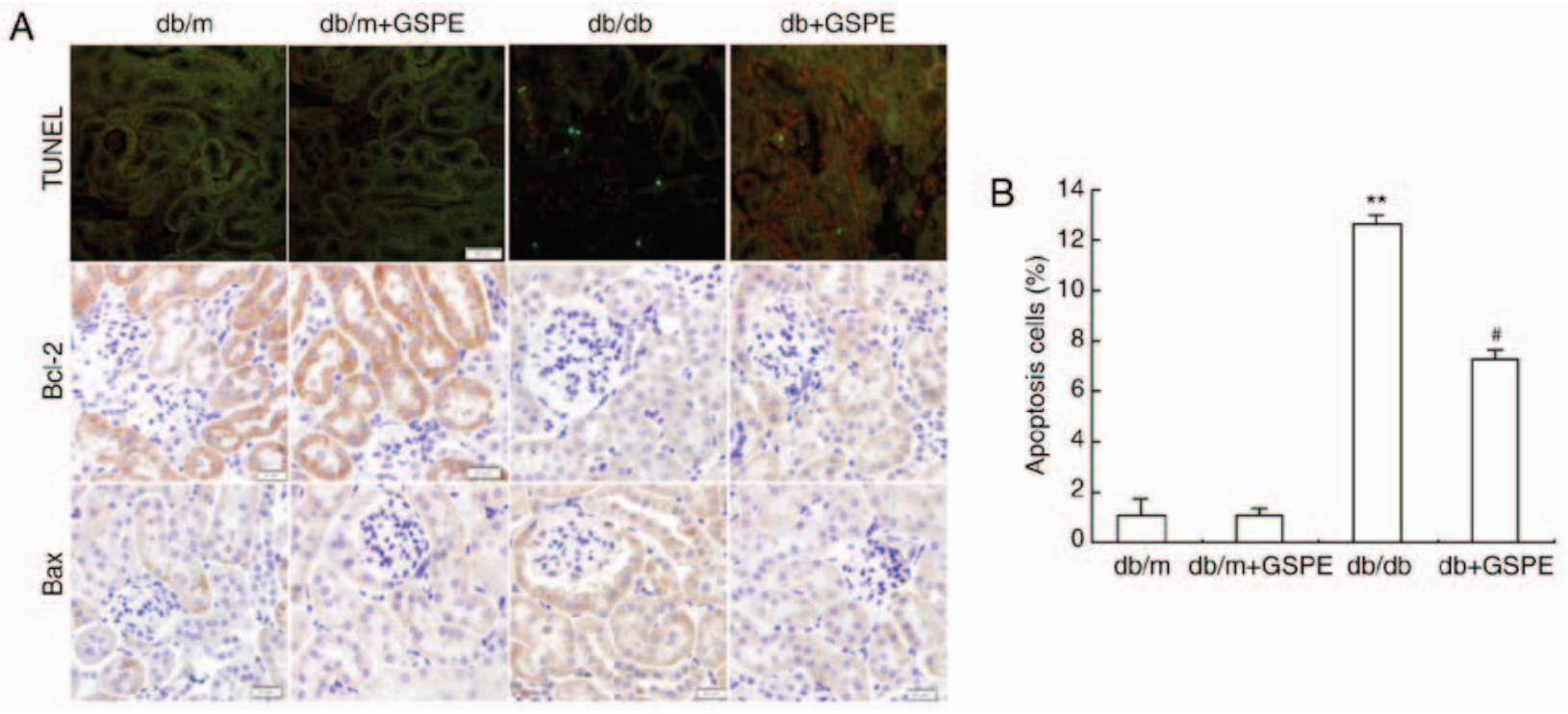

Figure 2. Effects of treatment with GSPE on apoptosis and Bcl-2/Bax expression in diabetic kidneys. (A) Apoptosis was determined using the TUNEL assay, and $\mathrm{Bcl}-2 / \mathrm{Bax}$ expression was determined by immunohistochemistry and (B) determination of the mean apoptotic cells per field (magnification, $\mathrm{x} 400$ ). Values are expressed as the mean \pm standard deviation. ${ }^{* *} \mathrm{P}<0.01 \mathrm{vs}$. db/m group; ${ }^{\sharp} \mathrm{P}<0.05 \mathrm{vs}$. db/db group. GSPE, grape seed procyanidin; TUNEL, terminal deoxynucleotidyl-transferase-mediated dUTP nick end labeling; Bax, Bcl-2-associated X protein; Bcl-2, B-cell lymphoma-2.

the $\mathrm{HG}+\mathrm{C} 3 \mathrm{G}$ group compared with the HG-treated group. Furthermore, the expression of cyt $c$ was demonstrated to be significantly suppressed in the HG group; however, this effect was significantly attenuated following treatment with C3G (Fig. 5C).

Treatment with C3G attenuates the HG-induced enhancement of TXNIP expression, suppression of TRX2 expression, suppression of TRX activity, alteration of $M M P$, and enhancement of ROS production in HK-2 cells. The authors' previous study demonstrated that TXNIP is involved in the HG-induced apoptosis of mouse mesangial cells, and that knockdown of TXNIP attenuates HG-induced suppression of TRX activity (18). As revealed in Fig. 6A-D, HK-2 cells under HG conditions demonstrated enhanced levels of MMP following treatment with $\mathrm{HG}$ for $48 \mathrm{~h}$. The HG-induced increase in MMP in HK-2 cells was significantly attenuated following treatment with C3G. In addition, to investigate whether TXNIP is involved in the protective effect of $\mathrm{C} 3 \mathrm{G}$ in $\mathrm{HK}-2$ cells under HG treatment, RT-qPCR analysis and western blotting were performed to determine the expression of TXNIP. Following treatment with HG for $48 \mathrm{~h}$, the expression levels of TXNIP mRNA were significantly increased in the HG group compared with the control group, whereas treatment with $\mathrm{C} 3 \mathrm{G}$ was revealed to significantly suppress HG-induced expression of TXNIP in HK-2 cells (Fig. 6E and F). Following this, the effect of $\mathrm{C} 3 \mathrm{G}$ treatment on TRX2 expression in HK-2 cells exposed to HG was investigated. As revealed in Fig. 6E, HG exposure did not markedly affect the expression of TRX2; however, the expression of TRX2 was significantly enhanced in the $\mathrm{HG}+\mathrm{C} 3 \mathrm{G}$ group compared with the HG group. Furthermore, the effect of treatment with $\mathrm{C} 3 \mathrm{G}$ on the activity of TRX in HK-2 cells under HG conditions was investigated. Furthermore, following exposure to $\mathrm{HG}$ for $48 \mathrm{~h}$, the activity of TRX was significantly suppressed, whereas treatment with $\mathrm{C} 3 \mathrm{G}$ under HG conditions significantly attenuated this effect (Fig. 6G).

These results suggest that $\mathrm{C} 3 \mathrm{G}$ treatment inhibits ROS production and suppresses MMP in HK-2 cells otherwise induced by $\mathrm{HG}$ conditions.

C3G suppresses HG-induced apoptosis via inhibition of p38 MAPK and ERK1/2 phosphorylation. The involvement of p38 MAPK and ERK1/2 in HG-induced apoptosis in renal tubular epithelial cells has previously been demonstrated (19). 

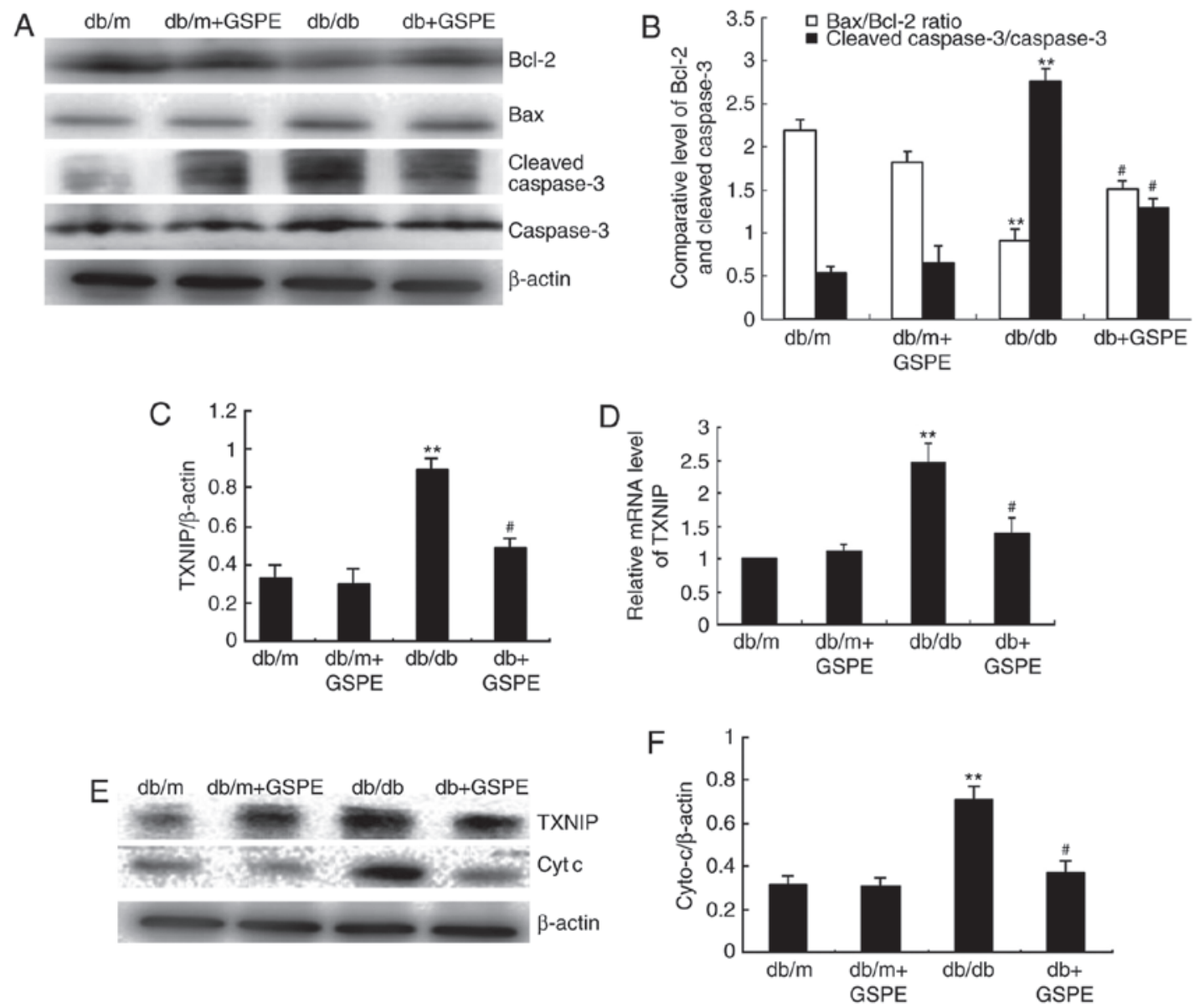

Figure 3. Effects of treatment with GSPE on the expression of apoptosis-associated proteins in diabetic kidneys. (A) The expression levels of cleaved caspase-3, caspase-3, Bcl-2 and Bax were determined via western blot analysis. (B) The relative intensity of cleaved caspase-3 was normalized to caspase-3. Normalization of Bax and Bcl-2 against $\beta$-actin was performed prior to determination of the Bax/Bcl-2 ratio. Treatment with GSPE significantly suppressed the expression of cleaved caspase-3 and suppressed the Bax/Bcl-2 ratio. (C) The protein and (D) mRNA expression of TXNIP was enhanced in the db/db group compared with $\mathrm{db} / \mathrm{m}$ mice; however, this increase was significantly attenuated by treatment with GSPE compared with $\mathrm{db} / \mathrm{db}$ group mice. (E) The protein expression of TXNIP and cyt $c$ was analyzed by western blotting. (F) The protein expression of cyt $c$ exhibited a similar trend to that observed with TXNIP. Values are expressed as mean \pm standard deviation. ${ }^{* *} \mathrm{P}<0.01 \mathrm{vs}$. db/m group; ${ }^{*} \mathrm{P}<0.05 \mathrm{vs}$. db/db group. GSPE, grape seed procyanidin; Bcl-2, B-cell lymphoma-2; Bax, Bcl-2-associated $\mathrm{X}$ protein; TXNIP, thioredoxin interacting protein; cyt $c$, cytochrome $c$.
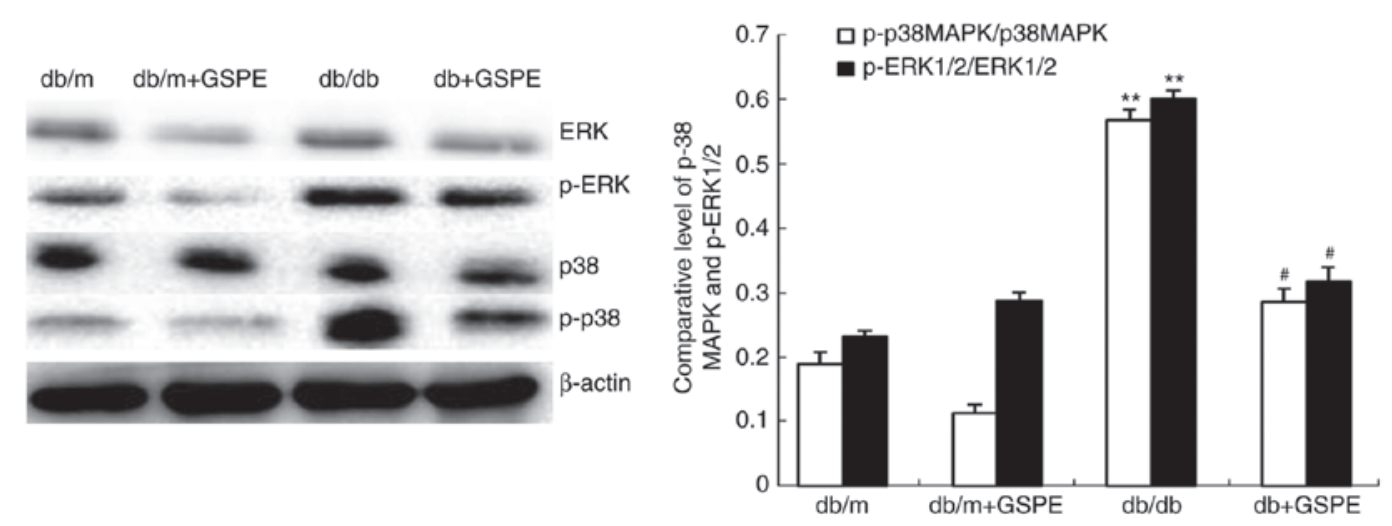

Figure 4. Treatment with GSPE enhances the phosphorylation of p38 MAPK and ERK1/2 in db/db mice. The expression levels of p-p38 MAPK, p38 MAPK, p-ERK1/2 and ERK1/2 were determined using western blotting, and the relative intensities of the p-p38 MAPK and p-ERK1/2 bands were normalized to the total p38 MAPK and ERK1/2, respectively. Values are expressed as the mean \pm standard deviation. ${ }^{* *} \mathrm{P}<0.01 \mathrm{vs}$. db/m group; ${ }^{\#} \mathrm{P}<0.05 \mathrm{vs}$. db/db group. GSPE, grape seed procyanidin; p38 MAPK, p38 mitogen-activated kinase; p-p38 MAPK, phosphorylated p38 MAPK; ERK1/2, extracellular signal-regulated kinase 1/2; p-ERK1/2, phosphorylated ERK1/2.

However, whether $\mathrm{C} 3 \mathrm{G}$ is involved in $\mathrm{HG}$-induced apoptosis via p38 MAPK and ERK1/2 associated pathways remains unclear. As demonstrated in Fig. 7A-C, the levels of p-p38 MAPK and
p-ERK1/2 were significantly increased following HG exposure, whereas treatment with $\mathrm{C} 3 \mathrm{G}$ significantly suppressed the HG-induced increase of p-p38 MAPK and p-ERK1/2 levels. 

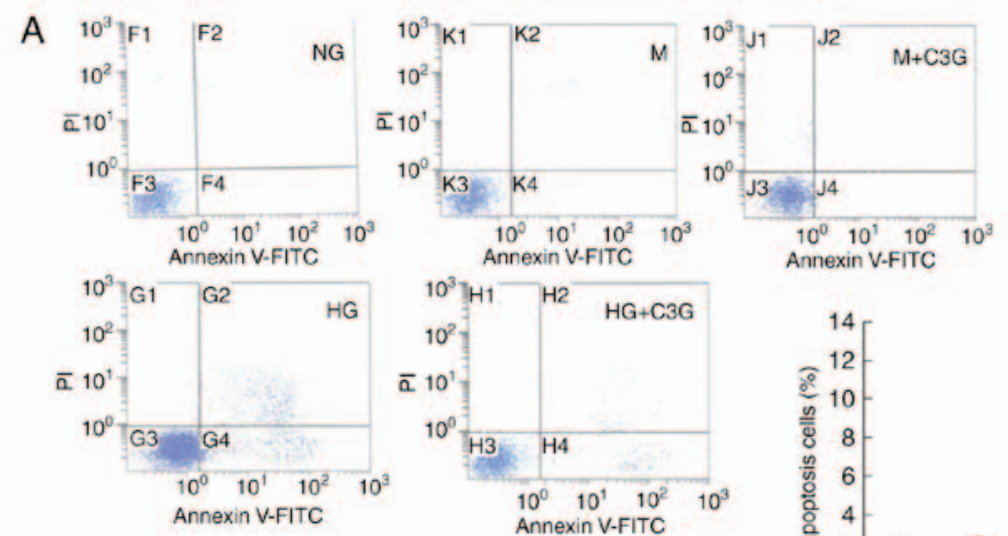

Annexin V-FITC
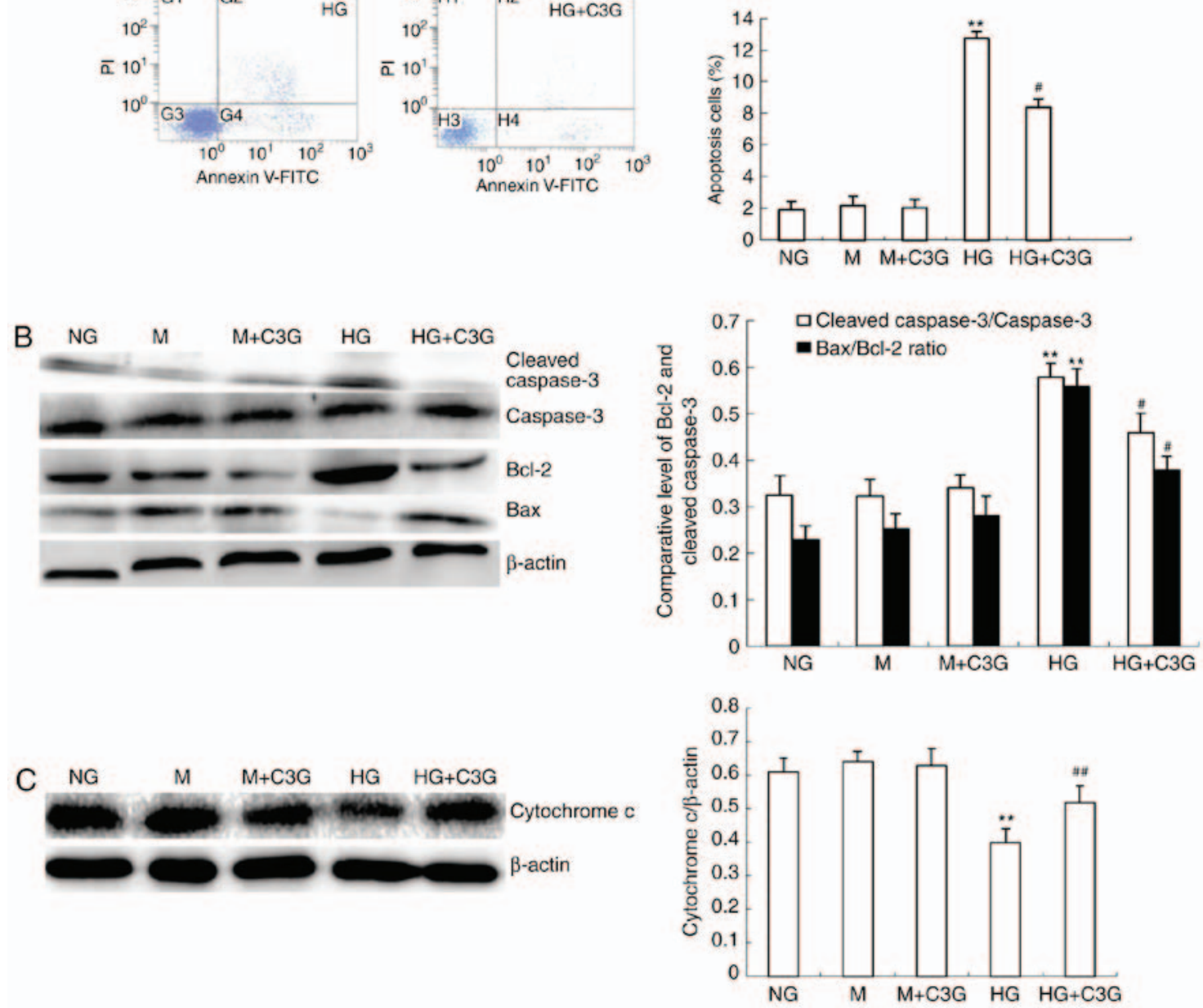

Figure 5. Treatment with C3G suppresses HG-induced apoptosis in HK-2 cells. HK-2 cells were incubated with NG (5.6 mM), NG + 24.4 mM M, M + C3G $(50 \mu \mathrm{M}, \mathrm{M}+\mathrm{C} 3 \mathrm{G}), \mathrm{HG}(30 \mathrm{mM})$ and $\mathrm{HG}+\mathrm{C} 3 \mathrm{G}(50 \mu \mathrm{M}, \mathrm{HG}+\mathrm{C} 3 \mathrm{G})$ for $48 \mathrm{~h}$. (A) Apoptosis was determined via flow cytometry. C3G was revealed to significantly suppress HG-induced cell apoptosis. (B) Expression levels of cleaved caspase-3, caspase-3, Bcl-2 and Bax were determined using western blotting. The relative intensity of the cleaved caspase- 3 band was normalized to the caspase- 3 band. Normalization of Bax and Bcl-2 against $\beta$-actin was performed prior to the determination of the Bax/Bcl-2 ratio. C3G treatment significantly suppressed HG-induced expression of cleaved caspase-3 and the Bax/Bcl-2 ratio. (C) Western blot analysis of cyt $c$ in cytosolic fractions of HK-2 cells. The relative intensity of cyt $c$ was normalized to $\beta$-actin. Cyt $c$ expression in the cytosol fraction was enhanced following exposure of HK-2 cells to HG for $48 \mathrm{~h}$; however, this effect was significantly attenuated by treatment with C3G. Values are expressed as the mean \pm standard deviation $(\mathrm{n}=6) .{ }^{* *} \mathrm{P}<0.01$ vs. NG; ${ }^{\prime \prime} \mathrm{P}<0.05$ and ${ }^{\# t} \mathrm{P}<0.01$ vs. HG. HG, high glucose; NG, no glucose; M, mannitol; C3G, cyanidin-3-O- $\beta$-glucoside chloride; cyt $c$, cytochrome $c$; Bcl-2, B-cell lymphoma-2; Bax, Bcl-2-associated X protein.

To investigate whether p38 MAPK or ERK1/2 signaling affects HG-induced apoptosis, HK-2 cells were treated with either specific p38 MAPK SB203580 $(10 \mu \mathrm{M})$ or ERK1/2 PD98059 $(50 \mu \mathrm{M})$ inhibitors for $0.5 \mathrm{~h}$. Following this, cells were incubated under HG conditions, in the presence of SB203580 or PD98059, for 48 h. Furthermore, the effects of p38 MAPK and ERK1/2 knockdown regarding apoptosis were investigated. HG exposure in HK-2 cells was revealed to significantly enhance cellular apoptosis compared with non-treated cells (Fig. 7D and E). In HK-2 cells, the increase in apoptosis exhibited by HG-treated cells was significantly suppressed following incubation with either SB203580 or PD98059 (Fig. 7D and E). In addition, administration of C3G to HG-treated HK-2 cells significantly attenuated the otherwise enhancement of apoptosis (Fig. 7D and E). In conclusion, these results suggested that HG-induced apoptosis may be attenuated by suppression of p38 MAPK and ERK1/2 phosphorylation in HK-2 cells via treatment with $\mathrm{C} 3 \mathrm{G}$.

\section{Discussion}

In the present study, it was demonstrated that treatment with GSPE in $\mathrm{db} / \mathrm{db}$ mice suppresses kidney cell apoptosis and superoxide production, thus suggesting that GSPE may have a therapeutic effect regarding DN. Furthermore, C3G was demonstrated to suppress HG-induced ROS generation, MMP, 

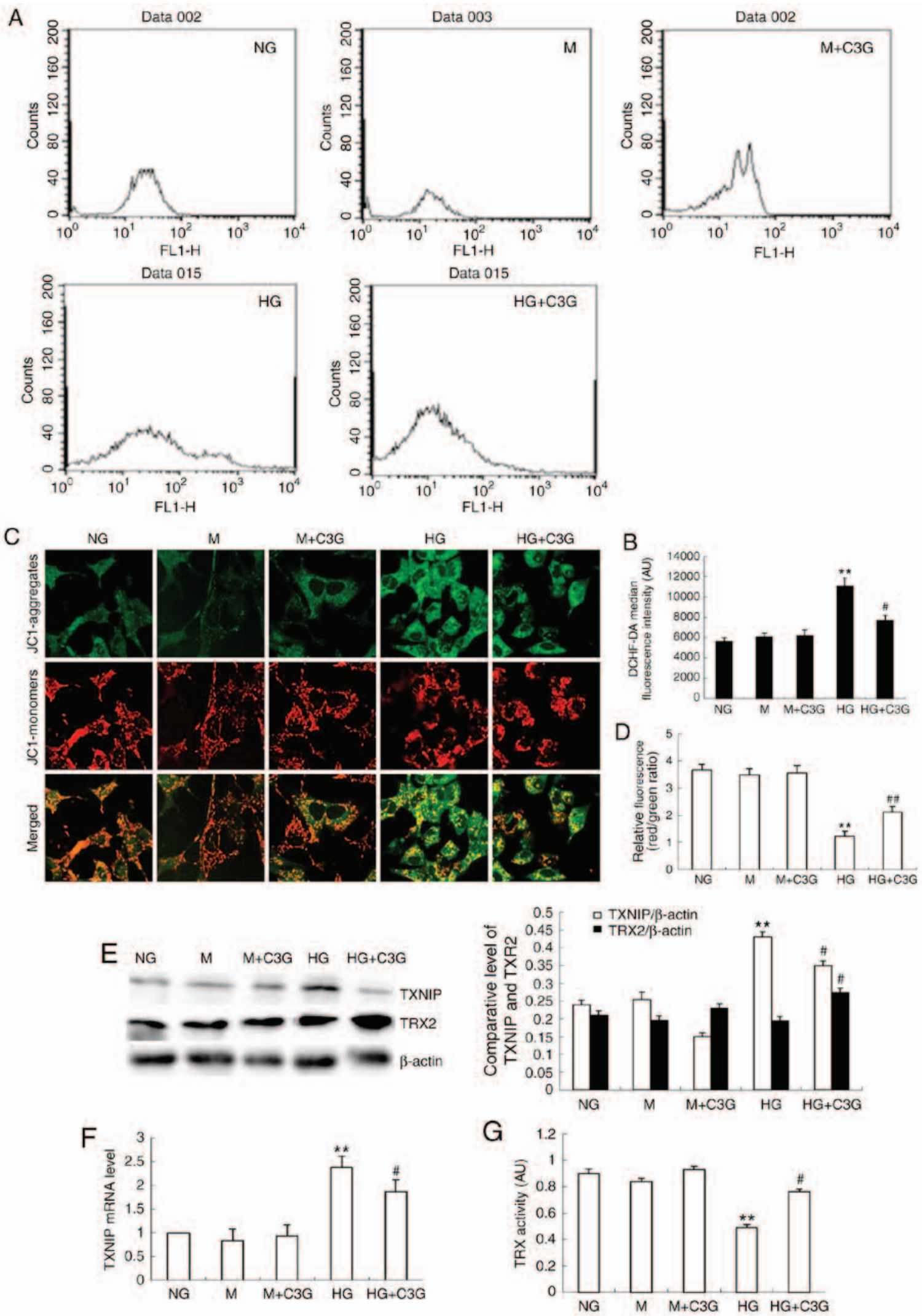

Figure 6. Effects of treatment with $\mathrm{C} 3 \mathrm{G}$ on HG-induced MMP and ROS production, expression of TXNIP and TRX2 expression and TRX activity in HK-2 cells. HK-2 cells were incubated with NG (5.6 mM), NG + $30 \mathrm{mM} \mathrm{M}, \mathrm{M}+\mathrm{C} 3 \mathrm{G}(50 \mu \mathrm{M}, \mathrm{M}+\mathrm{C} 3 \mathrm{G}), \mathrm{HG}(30 \mathrm{mM})$ and HG + C3G (50 $\mu \mathrm{M}, \mathrm{HG}+\mathrm{C} 3 \mathrm{G})$ for 48 h. (A) Intracellular ROS was determined via flow cytometry and (B) quantified. (C) MMP was determined using a fluorescent probe, JC1, and (D) quantified. The MMP loss was quantified from the shift of JC-1 emission from red ( $\sim 590 \mathrm{~nm})$ to green $(\sim 525 \mathrm{~nm})$. The ratio of red/green fluorescence represented MMP in HK-2 cells. Treatment with C3G significantly suppressed intracellular ROS production in HK-2 cells exposed to HG conditions. (E) The expression levels of TXNIP and TRX2 were determined using western blotting, and the relative intensities of the TXNIP and TRX2 bands were normalized to the $\beta$-actin band. (F) The mRNA expression of TXNIP was determined via reverse transcription-quantitative polymerase chain reaction. (G) TRX activity was determined using an insulin disulfide reduction assay. Values are expressed as mean \pm standard deviation $(\mathrm{n}=6) .{ }^{* *} \mathrm{P}<0.01$ vs. $\mathrm{NG}$; ${ }^{*} \mathrm{P}<0.05$ vs. HG. HG, high glucose; $\mathrm{NG}$, no glucose; M, mannitol; C3G, cyanidin-3-O- $\beta$-glucoside chloride; TXNIP, thioredoxin interacting protein; TRX, thioredoxin; TRX2, thioredoxin 2; MMP, mitochondrial membrane potential; DCHF-DA, dichloro-dihydro-fluorescein diacetate. 

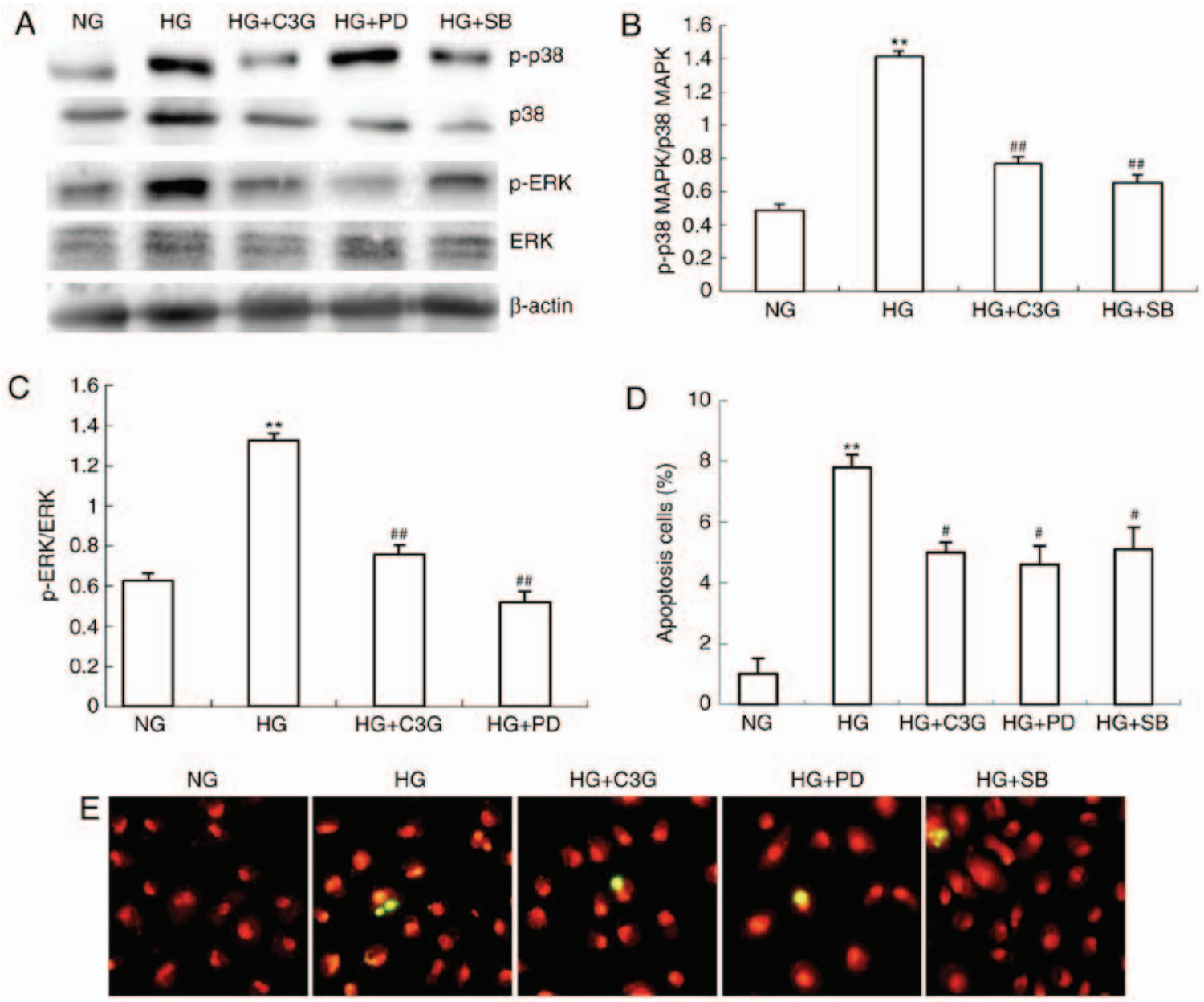

Figure 7. Treatment with C3G suppresses HG-induced phosphorylation of p38 MAPK and ERK1/2 in HK-2 cells. HK-2 cells were incubated with NG $(5.6 \mathrm{mM}), \mathrm{HG}(30 \mathrm{mM})$ and $\mathrm{HG}+\mathrm{C} 3 \mathrm{G}(50 \mu \mathrm{M}, \mathrm{HG}+\mathrm{C} 3 \mathrm{G})$ and $\mathrm{HG}+\mathrm{SB} 203580(10 \mu \mathrm{M}, \mathrm{HG}+\mathrm{SB}), \mathrm{HG}+\mathrm{PD} 94059(50 \mu \mathrm{M}, \mathrm{HG}+\mathrm{PD})$ for $48 \mathrm{~h}$. (A) Expression levels of p-p38 MAPK, p38 MAPK, p-ERK1/2 and ERK1/2 were determined by western blot analysis, and the relative intensities of (B) p-p38 MAPK and (C) p-ERK1/2 were normalized to total p38 MAPK and ERK1/2, respectively. (D) Apoptosis of HK-2 cells was determined via the terminal deoxynucleotidyl-transferase-mediated dUTP nick end labeling assay and (E) images were captured. Values are expressed as the mean \pm standard deviation ( $\mathrm{n}=6$; magnification, $\mathrm{x} 400)$. ${ }^{* * *} \mathrm{P}<0.01$ vs. NG; ${ }^{*} \mathrm{P}<0.05$ vs. HG. HG, high glucose; NG, no glucose; PD, PD94059; SB, SB203580; C3G, cyanidin-3-O- $\beta$-glucoside chloride; p38 MAPK, p38 mitogen-activated kinase; p-p38 MAPK, phosphorylated p38 MAPK; ERK1/2, extracellular signal-regulated kinase 1/2; p-ERK1/2, phosphorylated ERK1/2.

cyt $c$ translocation from the mitochondria to the cytoplasm, TXNIP expression, and the phosphorylation of p38 MAPK and ERK. In addition, $\mathrm{C} 3 \mathrm{G}$ was demonstrated to upregulate TRX2 expression, stabilize the biological activity of TRX and suppress HK-2 cellular apoptosis in response to hyperglycemia.

The enhancement of ROS production is an important feature of microvascular and macrovascular complications associated with deformity and death in patients with diabetes mellitus type $2(20,21)$. Furthermore, ROS levels have an important role in the pathogenesis of DN $(1,22)$. These results suggest that ordinary and catalytic antioxidants may exhibit protective properties against, or suppress the morbidity of, DN, and a combination of methods to suppress excessive production of ROS, and thus increase the elimination of preformed ROS, may serve as a potential therapeutic agent against the development and progression of DN. C3G has been suggested to possess vigorous antioxidant and anti-inflammatory properties $(23,24)$. Recent studies have revealed that $\mathrm{C} 3 \mathrm{G}$ is able to suppress 1,3-dichloro-2-propanol-induced ROS generation and suppress the apoptosis of R2C leydig cells (25). In a db/db model of DN, treatment with grape seed procyanidin B2 (GSPB2) was demonstrated to result in a suppression of triglyceride concentration in serum, total cholesterol level, advanced glycation end products and UAE, compared with vehicle-treated diabetic mice (26). Chronic exposure to Diquat significantly enhances granulosa cell damage, whereas treatment with GSPB2 suppresses granulosa cell apoptosis and causes the autophagy process in ICR mice (27). In the present study, the results suggested that $\mathrm{db} / \mathrm{db}$ mice demonstrated markedly enhanced UAE, total body weight and average glomerular volume at 12 weeks post-development of diabetes (19). In addition, treatment with GSPE in $\mathrm{db} / \mathrm{db}$ mice attenuated albuminuria and the level of urinary 8-OHdG. Furthermore, the results of the present study demonstrated that GSPE administration suppressed renal cell apoptosis in $\mathrm{db} / \mathrm{db}$ mice, thus suggesting that GSPE exhibits therapeutic effects on the diabetic kidney. However, Tyagi et al (28) and Li et al (29) suggested that procyanidin B2 leads to apoptosis in PCa cells of human prostate cancer and in endothelial cells of diabetes mellitus. The discrepancy between the results of the present study and previous studies may reflect differences in the chosen cell lines. 
Apoptosis contributes to the development of DN (30). Previous studies have suggested that HG-induced cellular apoptosis is an important factor in the development of kidney injury, and ROS results in the apoptosis of renal tubular cells $(31,32)$. A predominant factor of apoptosis is the accumulation of ROS, which enhances intracellular DNA damage and may induce cell apoptosis. C3G has been demonstrated to suppress hyperglycemia-induced liver oxidative damage by enhancing glutathione synthesis via a cyclic adenosine monophosphate-protein kinase A-dependent signaling pathway (33). In the present study, cellular apoptosis in $\mathrm{db} / \mathrm{db}$ mouse kidneys was significantly enhanced; however, this was attenuated by treatment with GSPE. In vitro, it was revealed that treatment with $\mathrm{C} 3 \mathrm{G}$ suppressed HG-induced ROS generation, apoptosis, the expression of cleaved caspase- 3 , the $\mathrm{Bax} / \mathrm{Bcl}-2$ ratio, and cyt $c$ translocation from the mitochondria to the cytoplasm in HK-2 cells. Furthermore, the results of the present study demonstrated that $\mathrm{C} 3 \mathrm{G}$ treatment reversed the $\mathrm{HG}$-induced alteration in MMP in HK-2 cells. The results suggest that anthocyanins may attenuate diabetic renal injury via suppression of ROS, and may thus protect mitochondrial function. Furthermore, the results suggest that the administration of anthocyanins enhances antioxidant function and decreases oxidative stress, thus suppressing apoptosis.

The TRX system, a predominant thiol antioxidant pathway, regulates the metabolic breakdown of intracellular ROS. TXNIP, first identified as the product of the 1,25-dihydroxyvitamin D-3 inducible gene in HL-cells (additionally termed vitamin D3 upregulated protein 1 or thioredoxin binding protein-2), is the endogenous inhibitor of cellular TRX, inhibiting its antioxidative role by combining with redox-active cysteine residues (34). TRX/TXNIP, a redox-sensitive signaling complex, may regulate cellular redox status and has an important role in the association of redox regulation with the etiopathogenesis of diseases (35). In a recent study, it was demonstrated that TXNIP is upregulated under $\mathrm{HG}$ conditions in mouse mesangial cells and renal cells, and that TXNIP knockout may attenuate the HG-induced suppression of TRX activity, and suppress HG-induced apoptosis and ROS generation $(10,18)$. In the present study, it was demonstrated that the administration of anthocyanins significantly suppressed TXNIP expression in the kidneys of $\mathrm{db} / \mathrm{db}$ mice and in HK-2 cells incubated under HG conditions. Furthermore, the results suggested that $\mathrm{C} 3 \mathrm{G}$ treatment enhanced TRX2 expression and attenuated the HG-induced suppression of TRX activity in HK-2 cells. These results suggest that anthocyanins attenuate oxidative stress in diabetic kidneys via regulation of TXNIP and TRX expression.

Increasing studies have suggested that an increase in the activity of p38 MAPK and ERK1/2 contributes to the etiopathogenesis of DN $(36,37)$. Numerous studies have suggested that GSPEs may protect the kidney by suppressing p38 MAPK and ERK1/2 phosphorylation $(38,39)$. In the present study, it was demonstrated that the expression levels of p-p38 MAPK and p-ERK1/2 were significantly suppressed in HK-2 cells following treatment with anthocyanin in vivo and in vitro, thus suggesting that a reduction in the $\mathrm{HG}$-induced phosphorylation of p38 MAPK and ERK1/2 may be a downstream effector of the anthocyanin associated pathway. Furthermore, the present study revealed that treatment with a p38 MAPK inhibitor (SB203580) or ERK inhibitor (PD98059) was able to suppress HG-induced apoptosis, thus suggesting that ROS-MAPK and ROS-ERK is involved in apoptosis.

The present study demonstrated that treatment with anthocyanins suppressed the TXNIP expression-enhanced p38 MAPK and ERK1/2 activity, and suppressed renal cellular apoptosis under diabetic conditions. Therefore, the results suggest that anthocyanins (GSPE and C3G) may serve as potential therapeutic agents for the treatment of DN.

\section{Acknowledgements}

The present study was supported by the Hebei High Education Science and Technology Foundation (grant no. NQ2015020), the Hebei Provincial Natural Science Fund (grant no.H2016206482), and the Hebei Science and Technology Department Program (grant no. 132777190).

\section{Competing interests}

The authors declare that they have no competing interests.

\section{References}

1. Miranda-Díaz AG, Pazarín-Villaseñor L, Yanowsky-Escatell FG and Andrade-Sierra J: Oxidative stress in diabetic nephropathy with early chronic kidney disease. J Diabetes Res 2016: 7047238, 2016.

2. Pesce C, Menini S, Pricci F, Favre A, Leto G, DiMario U and Pugliese G: Glomerular cell replication and cell loss through apoptosis in experimental diabetes mellitus. Nephron 90: 484-488, 2002.

3. Devine PJ, Perreault SD and Luderer U: Roles of reactive oxygen species and antioxidants in ovarian toxicity. Biol Reprod 86: 27, 2012.

4. Fujii J, Iuchi Y and Okada F: Fundamental roles of reactive oxygen species and protective mechanisms in the female reproductive system. Reprod Biol Endocrinol 3: 43, 2005.

5. Sena LA and Chandel NS: Physiological roles of mitochondrial reactive oxygen species. Mol Cell 48: 158-167, 2012.

6. Wu H, Shi Y, Deng X, Su Y, Du C, Wei J, Ren Y, Wu M, Hou Y and Duan H: Inhibition of c-Src/p38 MAPK pathway ameliorates renal tubular epithelial cells apoptosis in $\mathrm{db} / \mathrm{db}$ mice. Mol Cell Endocrinol 417: 27-35, 2015.

7. Kanwar YS, Wada J, Sun L, Xie P, Wallner EI, Chen S, Chugh S and Danesh FR: Diabetic nephropathy: Mechanisms of renal disease progression. Exp Biol Med (Maywood) 233: 4-11, 2008.

8. Sun L, Dutta RK, Xie P and Kanwar YS: Myo-inositol oxygenase overexpression accentuates generation of reactive oxygen species and exacerbates cellular injury following high glucose ambience: A new mechanism relevant to the pathogenesis of diabetic nephropathy. J Biol Chem 291: 5688-5707, 2016.

9. Mishra R, Emancipator SN, Kern T and Simonson MS: High glucose evokes an intrinsic proapoptotic signaling pathway in mesangial cells. Kidney Int 67: 82-93, 2005.

10. Wei J, Shi Y, Yan J, Ren Y, Du C, Zhang L, Li Y and Duan H: Knockdown of thioredoxin-interacting protein ameliorates high glucose-inducedepithelialtomesenchymaltransitioninrenaltubular epithelial cells. Cell Signal 25: 2788-2796, 2013.

11. Punithavathi VR, Stanely Mainzen Prince P, Kumar MR and Selvakumari CJ: Protective effects of gallic acid on hepatic lipid peroxide metabolism, glycoprotein components and lipids in streptozotocin-induced type II diabetic Wistar rats. J Biochem Mol Toxicol 25: 68-76, 2011.

12. Takikawa $M$, Inoue $\mathrm{S}$, Horio $\mathrm{F}$ and Tsuda $\mathrm{T}$ : Dietary anthocyanin-rich bilberry extract ameliorates hyperglycemia and insulin sensitivity via activation of AMP-activated protein kinase in diabetic mice. J Nutr 140: 527-533, 2010.

13. Kang MK, Li J, Kim JL, Gong JH, Kwak SN, Park JH, Lee JY, Lim SS and Kang YH: Purple corn anthocyanins inhibit diabetes-associated glomerular monocyte activation and macrophage infiltration. Am J Physiol Renal Physiol 303: F1060-F1069, 2012. 
14. Du C, Shi Y, Ren Y, Wu H, Yao F, Wei J, Wu M, Hou Y and Duan H: Anthocyanins inhibit high-glucose-induced cholesterol accumulation and inflammation by activating LXR $\alpha$ pathway in HK-2 cells. Drug Des Devel Ther 9: 5099-5113, 2015.

15. Rota C, Chignell CF and Mason RP: Evidence for free radical formation during the oxidation of 2'-7'-dichlorofluorescin to the fluorescent dye 2'-7'-dichlorofluorescein by horseradish peroxidase: Possible implications for oxidative stress measurements. Free Radic Biol Med 27: 873-881, 1999.

16. Holmgren A and Björnstedt M: Thioredoxin and thioredoxin reductase. Methods Enzymol 252: 199-208, 1995.

17. Livak KJ and Schmittgen TD: Analysis of relative gene expression data using real-time quantitative PCR and the 2(-Delta Delta C(T)) method. Methods 25: 402-408, 2001.

18. Shi Y, Ren Y, Zhao L, Du C, Wang Y, Zhang Y, Li Y, Zhao S and Duan H: Knockdown of thioredoxin interacting protein attenuates high glucose-induced apoptosis and activation of ASK1 in mouse mesangial cells. FEBS Lett 585: 1789-1795, 2011.

19. Bocanegra V, Gil Lorenzo AF, Cacciamani V, Benardón ME, Costantino VV and Vallés PG: RhoA and MAPK signal transduction pathways regulate NHE1-dependent proximal tubule cell apoptosis after mechanical stretch. Am J Physiol Renal Physiol 307: F881-F889, 2014.

20. Hammes HP: Pathophysiological mechanisms of diabetic angiopathy. J Diabetes Complications 17 (Suppl 2): S16-S19, 2003.

21. Suganya N, Bhakkiyalakshmi E, Sarada DV and Ramkumar KM: Reversibility of endothelial dysfunction in diabetes: Role of polyphenols. Br J Nutr 116: 223-246, 2016.

22. Ha H, Hwang IA, Park JH and Lee HB: Role of reactive oxygen species in the pathogenesis of diabetic nephropathy. Diabetes Res Clin Pract 82 (Suppl 1): S42-S45, 2008.

23. Speciale A, Canali R, Chirafisi J, Saija A, Virgili F and Cimino F: Cyanidin-3-O-glucoside protection against TNF- $\alpha$-induced endothelial dysfunction: Involvement of nuclear factor- $\kappa \mathrm{B}$ signaling. J Agric Food Chem 58: 12048-12054, 2010.

24. Sivasinprasasn S, Pantan R, Thummayot S, Tocharus J, Suksamrarn A and Tocharus C: Cyanidin-3-glucoside attenuates angiotensin II-induced oxidative stress and inflammation in vascular endothelial cells. Chem Biol Interact: Oct 28, 2016 (Epub ahead of print)

25. Sun J, Xu W, Zhu C, Hu Y, Jiang X, Ou S, Su Z, Huang Y, Jiao R and Bai W: Cyanidin-3-O-glucoside protects against 1,3-dichloro-2-propanol-induced reduction of progesterone by Up-regulation of Steroidogenic Enzymes and cAMP level in leydig cells. Front Pharmacol 7: 399, 2016.

26. Zhou Y, Li BY, Li XL, Wang YJ, Zhang Z, Pei F, Wang QZ, Zhang J, Cai YW, Cheng M and Gao HQ: Restoration of Mimecan expression by grape seed procyanidin B2 through regulation of nuclear Factor-kappaB in mice with diabetic nephropathy. Iran J Kidney Dis 10: 325-331, 2016.

27. Zhang JQ, Gao BW, Wang J, Ren QL, Chen JF, Ma Q, Zhang ZJ and Xing BS: Critical role of FoxO1 in granulosa cell apoptosis caused by oxidative` stress and protective effects of grape seed procyanidin B2. Oxid Med Cell Longev 2016: 6147345, 2016.
28. Tyagi A, Raina K, Shrestha SP, Miller B, Thompson JA, Wempe MF, Agarwal R and Agarwal C: Procyanidin B2 3,3'-di-O-gallate, a biologically active constituent of grape seed extract, induces apoptosis in human prostate cancer cells via targeting NF- $\kappa \mathrm{B}$, Stat 3 and AP1 transcription factors. Nutr Cancer 66: 736-746, 2014.

29. Li BY, Li XL, Cai Q, Cao HQ, Cheng M, Zhang JH, Wang JF, $\mathrm{Yu} F$ and Zhou RH: Induction of lactadherin mediates the apoptosis of endothelial cells in response to advanced glycation end products and protective effects of grape seed procyanidin B2 and resveratrol. Apoptosis 16: 732-745, 2011.

30. Sanchez-Niño MD, Sanz AB, Lorz C, Gnirke A, Rastaldi MP, Nair V, Egido J, Ruiz-Ortega M, Kretzler M and Ortiz A: BASP1 promotes apoptosis in diabetic nephropathy. J Am Soc Nephrol 21: 610-621, 2010.

31. Wu Y, Zhang M, Liu R and Zhao C: Oxidative Stress-activated NHE1 is involved in high Glucose-induced apoptosis in renal tubular epithelial cells. Yonsei Med J 57: 1252-1259, 2016.

32. Havasi A and Dong Z: Autophagy and tubular cell death in the kidney. Semin Nephrol 36: 174-188, 2016.

33. Zhu W, Jia Q, Wang Y, Zhang Y and Xia M: The anthocyanin cyanidin-3-O- $\beta$-glucoside, a flavonoid, increases hepatic glutathione synthesis and protects hepatocytes against reactive oxygen species during hyperglycemia: Involvement of a cAMP-PKA-dependent signaling pathway. Free Radic Biol Med 52: 314-327, 2012.

34. Ren Y, Shi Y, Wang Y, Li Y, Wu S, Li H, Zhang Y and Duan H: p38 MAPK pathway is involved in high glucose-induced thioredoxin interacting protein induction in mouse mesangial cells. FEBS Lett 584: 3480-3485, 2010.

35. Yoshihara E, Masaki S, Matsuo Y, Chen Z, Tian H and Yodoi J: Thioredoxin/Txnip: Redoxisome, as a redoxs witch for the pathogenesis of diseases. Front Immunol 4: 514, 2014.

36. Sakai N, Wada T, Furuichi K, Iwata Y, Yoshimoto K, Kitagawa K, Kokubo S, Kobayashi M, Hara A, Yamahana J, et al: Involvement of extracellular signal-regulated kinase and p38 in human diabetic nephropathy. Am J Kidney Dis 45: 54-65, 2005.

37. Zhou X, Liu R, Duan S, Huang G, Ye Y and Kong Y: High glucose enhances oxLDL-induced apoptosis in human renal proximal tubular epithelial cells largely via inducing Lectin-Like ox-LDL receptor-1. Pharmacology 98: 20-28, 2016.

38. Zhang Z, Li BY, Li XL, Cheng M, Yu F, Lu WD, Cai Q, Wang JF, Zhou RH, Gao HQ and Shen L: Proteomic analysis of kidney and protective effects of grape seed procyanidin B2 in $\mathrm{db} / \mathrm{db}$ mice indicate MFG-E8 as a key molecule in the development of diabetic nephropathy. Biochim Biophys Acta 1832: 805-816, 2013.

39. Takami Y, Uto H, Takeshita M, Kai H, Akamatsu E, Moriuchi A, Hasegawa S, Oketani M, Ido A, Kataoka $\mathrm{H}$ and Tsubouchi H: Proanthocyanidin derived from the leaves of Vaccinium virgatum suppresses platelet-derived growth factor-induced proliferation of the human hepatic stellate cell line LI90. Hepatol Res 40: 337-345, 2010.

This work is licensed under a Creative Commons Attribution-NonCommercial-NoDerivatives 4.0 International (CC BY-NC-ND 4.0) License. 